\title{
Bone mineral density of the lumbar spine of Brazilian children and adolescents aged 6 to 14 years
}

\author{
A.S.M. Fonseca ${ }^{1}$, \\ V.L. Szejnfeld ${ }^{2}$, \\ M.T. Terreri3, \\ J. Goldenberg', \\ M.B. Ferraz ${ }^{2}$ \\ and M.O.E. Hilário ${ }^{3}$
}

\author{
${ }^{1}$ Departamento de Pediatria, Universidade Federal do Rio Grande do Norte, \\ Natal, RN, Brasil \\ 2Divisão de Reumatologia, Departamento de Medicina and \\ ${ }^{3}$ Divisão de Alergia, Imunologia e Reumatologia, Departamento de Pediatria, \\ Escola Paulista de Medicina, Universidade Federal de São Paulo, São Paulo, SP, Brasil
}

\section{Correspondence}

M.T. Terreri

Rua Loefgreen, 2381, Apto 141

04040-004 São Paulo, SP

Brasil

Fax: + 55-11-5579-1590

E-mail: terreri@ uninet.com.br

Publication supported by FAPESP.

Received September 27, 1999

Accepted December 20, 2000

\section{Abstract}

The authors performed a study of bone mass in eutrophic Brazilian children and adolescents using dual-energy X-ray absorptiometry (DXA) in order to obtain curves for bone mineral content (BMC) and bone mineral density (BMD) by chronological age and correlate these values with weight and height. Healthy Caucasian children and adolescents, 120 boys and 135 girls, 6 to 14 years of age, residents of São Paulo, Brazil, were selected from the Pediatric Department outpatient clinic of Hospital São Paulo (Universidade Federal de São Paulo). $\mathrm{BMC}, \mathrm{BMD}$ and the area of the vertebral body of the L2-L4 segment were obtained by DXA. BMC and BMD for the lumbar spine (L2-L4) presented a progressive increase between 6 and 14 years of age in both sexes, with a distribution that fitted an exponential curve. We identified an increase of mineral content in female patients older than 11 years which was maintained until 13 years of age, when a new decrease in the velocity of bone mineralization occurred. Male patients presented a period of accelerated bone mass gain after 11 years of age that was maintained until 14 years of age. At 14 years of age the mean BMD values for boys and girls were 0.984 and $1.017 \mathrm{~g} / \mathrm{cm}^{2}$, respectively. A stepwise multiple regression analysis of paired variables showed that the "vertebral area-age" pair was the most significant in the determination of BMD values and the introduction of a third variable (weight or height) did not significantly increase the correlation coefficient.

\section{Introduction}

The increase of the life span in developing countries has made osteoporosis a major health issue, as already observed in developed countries (1). The problems concerning the control of loss of bone mass after adulthood, which is a characteristic of this

\section{Key words}

- Bone mineral density

- Lumbar spine densitometry

- Children

- Adolescents disease, have raised increased interest regarding prophylactic procedures, such as the achievement of an adequate bone mass peak $(2,3)$, since the bone mass present at any time during adulthood is the ratio between the amount obtained during adulthood and the loss caused by the aging process (4).

Despite the different opinions about the 
period when this bone peak is reached (5-8), there is general agreement that the peak of the bone mineral density (BMD) is acquired up to the end of puberty (9-11), a fact that has caused a rise of interest in the study of bone mineral content (BMC) during childhood and adolescence.

Dual-energy X-ray absorptiometry (DXA), with its low radiation dose and high accuracy and precision, has been extensively employed to measure bone mass in children and adolescents.

The authors performed a study of bone mass in eutrophic children and adolescents using DXA in order to obtain curves for $\mathrm{BMC}$ and $\mathrm{BMD}$ according to chronological age which would allow later comparisons with groups of children and adolescents with diseases or other osteopenia-inducing conditions and to correlate these values with anthropometric data.

\section{Material and Methods}

Healthy Caucasian children and adolescents, 120 boys and 135 girls aged 6 to 14 years, residents of São Paulo, Brazil, were selected from the Pediatric Department of Hospital São Paulo (Universidade Federal de São Paulo), from May 1995 to January 1998, and invited to take part in this study. The exclusion criteria were history of endocrinopathy, nephropathy, gastroenteropathy, or rheumatic diseases, bronchial asthma, malnutrition, short stature (below the 10th percentile), obesity (more than $120 \%$ of weight for height), premature birth, prolonged immobility period (more than two weeks), history of two or more accidental fractures or one pathological bone fracture, and treatment with corticosteroids or other drugs that affect bone metabolism.

All children were assessed clinically by a pediatrician (author A.S.M. Fonseca). Weight and height were measured with an electronic scale and a wall anthropometer.

$\mathrm{BMC}(\mathrm{g}), \mathrm{BMD}\left(\mathrm{g} / \mathrm{cm}^{2}\right)$, and the area of the vertebral body of the L2-L4 segment $\left(\mathrm{cm}^{2}\right)$, were measured with a commercially available DXA unit (DPX, Lunar Radiation Corp., Madison, WI, USA) using a medium mode scan. BMD was measured only in the lumbar spine because evaluation of the femoral neck may be biased due to the presence of growth cartilage and to the technical difficulties related to positioning this age group.

\section{Statistical analysis}

The Kruskal-Wallis test was used to compare the values of BMD, BMC, vertebral area (VA), weight and height between genders. Multiple linear regression analyses of BMD, BMC, VA (L2-L4), weight, height and age, with BMC and BMD as dependent variables, were performed by the stepwise, forward and backward methods. The statistical package SPSS/PC was used to process the data. The level of significance was set at 0.05 .

\section{Results}

The mean values of BMC, BMD, VA (L2-L4), weight and height for age and gender with their standard deviations are shown in Tables 1 and 2.

BMC and BMD for the lumbar spine (L2L4) showed a progressive increase between 6 and 14 years of age in both sexes, presenting a distribution that fitted an exponential curve (Figures 1 and 2). This distribution showed that the increase in bone mass was not steady, with periods of distinct rates of bone mineralization being observed.

Girls aged 6 to 10 years presented a period of slight increase in bone mass. We identified an increase of mineral content in girls older than 10 years which was maintained until 13 years of age, when a new decrease in the velocity of bone mineralization occurred.

Boys also presented an initial period of less intense mineralization that continued 
until 11 years of age, followed by a period of accelerated bone mass gain that was maintained until 14 years of age.

A significant difference between the BMD at 6 years and BMD at 11 years and older was observed in both sexes $(\mathrm{H}$ observed $=$ 98.1 and 62.7 for girls and boys, respectively; $\mathrm{H}$ critical $=15.5 ; \mathrm{P}<0.05)$.

The values of BMD between 6 and 14 years of age increased by 54 and $59 \%$ in boys and girls, respectively. At 14 years of age the mean BMD values were 0.984 and $1.017 \mathrm{~g} /$ $\mathrm{cm}^{2}$, which corresponds to 81 and $85 \%$ of the expected bone density for Brazilian Caucasian men and women between 35 and 40 years of age, respectively (12).

Analysis of the relationship between weight and height and bone mass showed a striking correlation between $\mathrm{BMC}$ and the following variables: VA $\left(\mathrm{r}^{2}=0.91\right.$ and 0.87 for females and males, respectively), weight $\left(r^{2}=0.73\right.$ and 0.69 , respectively) and height $\left(r^{2}=0.70\right.$ and 0.76 , respectively). However, after adjustment for VA and age, weight and

Table 1 - Weight, height, vertebral area (L2-L4), BMC and BMD according to age, in females ( $N=134$ ).

$\mathrm{BMC}=$ Bone mineral content; $\mathrm{BMD}=$ bone mineral density. Data are reported as means $\pm \mathrm{SD}$. Kruskal-Wallis test: $\mathrm{H}$ observed $=98.1 ; \mathrm{H}$ critical $=15.5(\mathrm{P}<0.05)$. Multiple comparison test: 6 years $<11,12,13,14$ years, 7 years $<12,13,14$ years, 8 years $<12,13,14$ years, 9 years $<12,13,14$ years, 10 years $<13,14$ years.

\begin{tabular}{rrrrccc}
\hline Age & $\mathrm{N}$ & Weight $(\mathrm{kg})$ & Height $(\mathrm{cm})$ & $\begin{array}{c}\text { Vertebral } \\
\text { area }\left(\mathrm{cm}^{2}\right)\end{array}$ & BMC $(\mathrm{g})$ & BMD $\left(\mathrm{g} / \mathrm{cm}^{2}\right)$ \\
\hline 6 & 8 & $22.21 \pm 2.81$ & $118.6 \pm 3.2$ & $19.38 \pm 1.7$ & $12.37 \pm 1.74$ & $0.640 \pm 0.035$ \\
7 & 8 & $27.11 \pm 4.54$ & $127.4 \pm 7.9$ & $22.83 \pm 2.7$ & $15.44 \pm 2.22$ & $0.670 \pm 0.076$ \\
8 & 17 & $31.10 \pm 4.91$ & $128.9 \pm 3.7$ & $23.07 \pm 2.26$ & $16.88 \pm 3.22$ & $0.725 \pm 0.075$ \\
9 & 19 & $32.21 \pm 4.00$ & $134.3 \pm 4.3$ & $24.32 \pm 2.96$ & $17.76 \pm 2.96$ & $0.728 \pm 0.050$ \\
10 & 16 & $36.41 \pm 4.78$ & $139.9 \pm 4.6$ & $26.07 \pm 3.09$ & $19.47 \pm 3.25$ & $0.745 \pm 0.067$ \\
11 & 18 & $38.26 \pm 3.76$ & $145.7 \pm 6.1$ & $28.40 \pm 4.27$ & $24.65 \pm 6.44$ & $0.857 \pm 0.117$ \\
12 & 15 & $44.35 \pm 4.09$ & $147.4 \pm 5.4$ & $32.43 \pm 3.33$ & $28.51 \pm 4.88$ & $0.875 \pm 0.086$ \\
13 & 15 & $48.15 \pm 4.10$ & $156.3 \pm 4.9$ & $35.12 \pm 2.23$ & $36.54 \pm 4.23$ & $1.040 \pm 0.095$ \\
14 & 19 & $49.35 \pm 6.48$ & $155.5 \pm 5.9$ & $37.05 \pm 3.41$ & $37.79 \pm 5.92$ & $1.017 \pm 0.106$
\end{tabular}

Table 2 - Weight, height, vertebral area (L2-L4), BMC and BMD according to age, in males ( $\mathrm{N}=120)$.

$\mathrm{BMC}=$ Bone mineral content; $\mathrm{BMD}=$ bone mineral density. Data are reported as means \pm SD. Kruskal-Wallis test: $\mathrm{H}$ observed $=62.7 ; \mathrm{H}$ critical $=15.5(\mathrm{P}<0.05)$. Multiple comparison test: 6 years $<11,12,13,14$ years, 7 years $<12,13,14$ years, 8 years $<12,13,14$ years, 9 years $<13$ years.

\begin{tabular}{ccccccc}
\hline Age & $\mathrm{N}$ & Weight $(\mathrm{kg})$ & Height $(\mathrm{cm})$ & $\begin{array}{c}\text { Vertebral } \\
\text { area }\left(\mathrm{cm}^{2}\right)\end{array}$ & BMC $(\mathrm{g})$ & BMD $\left(\mathrm{g} / \mathrm{cm}^{2}\right)$ \\
\hline 6 & 10 & $23.12 \pm 2.88$ & $117.9 \pm 3.1$ & $19.38 \pm 1.70$ & $12.28 \pm 1.74$ & $0.641 \pm 0.059$ \\
7 & 14 & $26.38 \pm 2.31$ & $128.6 \pm 4.4$ & $23.19 \pm 2.33$ & $14.98 \pm 1.89$ & $0.660 \pm 0.059$ \\
8 & 19 & $28.25 \pm 2.76$ & $128.9 \pm 3.9$ & $22.77 \pm 1.48$ & $15.93 \pm 1.31$ & $0.700 \pm 0.042$ \\
9 & 12 & $32.07 \pm 4.60$ & $134.1 \pm 4.9$ & $26.27 \pm 2.41$ & $18.72 \pm 2.61$ & $0.711 \pm 0.056$ \\
10 & 17 & $33.04 \pm 4.13$ & $138.0 \pm 2.4$ & $25.68 \pm 2.74$ & $18.91 \pm 2.51$ & $0.725 \pm 0.064$ \\
11 & 17 & $38.45 \pm 5.98$ & $147.6 \pm 5.6$ & $29.30 \pm 2.98$ & $22.16 \pm 3.55$ & $0.756 \pm 0.068$ \\
12 & 11 & $39.02 \pm 3.63$ & $147.4 \pm 5.4$ & $30.47 \pm 3.19$ & $22.17 \pm 4.10$ & $0.825 \pm 0.073$ \\
13 & 16 & $47.77 \pm 8.67$ & $156.3 \pm 8.6$ & $33.58 \pm 4.74$ & $29.81 \pm 7.20$ & $0.890 \pm 0.142$ \\
14 & 4 & $55.02 \pm 4.24$ & $162.0 \pm 5.9$ & $37.05 \pm 3.41$ & $37.59 \pm 7.41$ & $0.984 \pm 0.134$
\end{tabular}


height did not show an additional effect on BMC, as demonstrated by multiple regression analysis and for this reason we chose the regression equation that considers $\mathrm{VA}$ and child age $(\mathrm{BMC}=-17.468+1.246 \mathrm{VA}+$ 0.618 age, $\mathrm{r}^{2}=0.92$ for girls and $\mathrm{BMC}=$ $-12.102+1.059 \mathrm{VA}+0.423$ age, $\mathrm{r}^{2}=0.87$ for boys).

A less intense, though equally important, correlation was observed for BMD compared to BMC: VA $\left(r^{2}=0.68\right.$ and 0.52 for females and males, respectively), weight $\left(\mathrm{r}^{2}\right.$

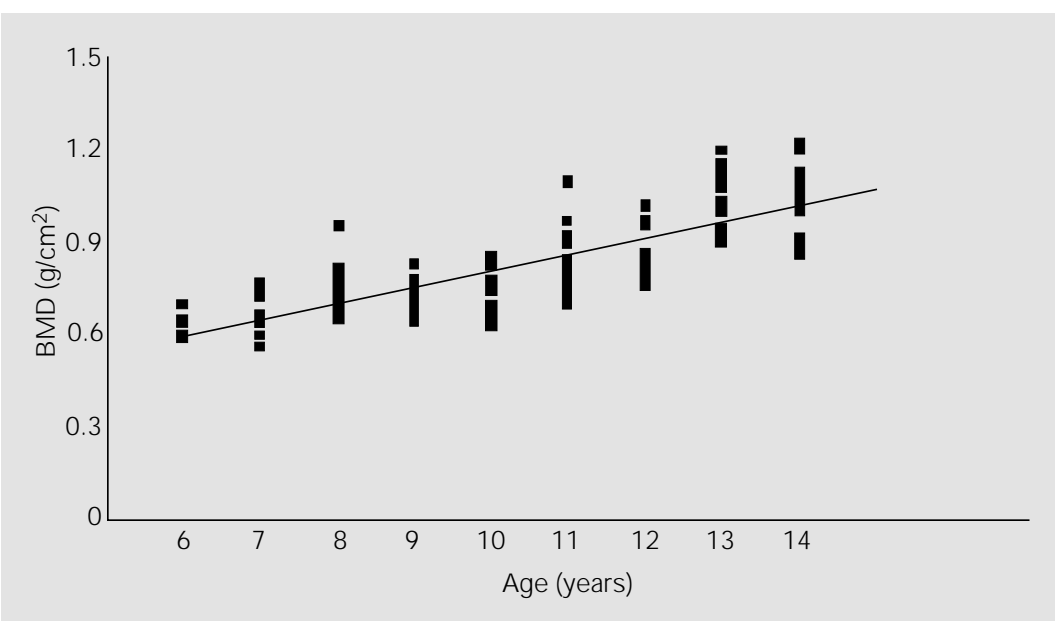

Figure 1 - Bone mineral density (BMD) values for the lumbar spine (L2-L4) as a function of age in female children and adolescents.

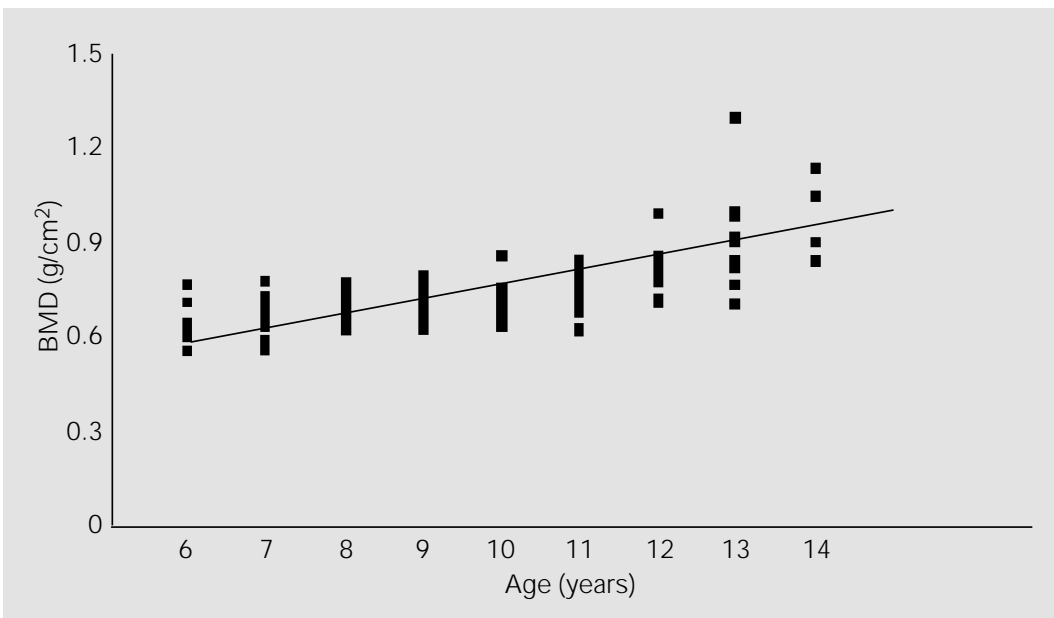

Figure 2 - Bone mineral density (BMD) values for the lumbar spine (L2-L4) as a function of age in male children and adolescents.
$=0.62$ and 0.45 , respectively $)$ and height $\left(\mathrm{r}^{2}\right.$ $=0.59$ and 0.49 , respectively). During the stepwise multiple regression analysis, the results for paired variables again showed that the "VA-age" pair was the most significant. The introduction of a third variable (weight or height), as previously observed with $\mathrm{BMC}$, did not cause a significant increase in the correlation coefficient $\left(\mathrm{r}^{2}\right)$ and for this reason the regression equation for vertebral area and child age was chosen $\left(\mathrm{BMD}=0.225+0.012 \mathrm{VA}+0.025 \mathrm{age}, \mathrm{r}^{2}=\right.$ 0.72 for girls and $\mathrm{BMD}=0.336+0.099 \mathrm{VA}$ +0.017 age, $r^{2}=0.55$ for boys).

\section{Discussion}

The mean values of BMD in the lumbar spine per age range obtained in our study were equivalent to those obtained in studies performed with a smaller group of Finnish children (13) using similar equipment (Lunar DPX, Medium mode).

The values of BMC and BMD in the lumbar spine showed a progressive increase with age, a kind of distribution that approached an exponential function, as also observed by others (14). This arching relationship was determined by the variation in the velocity of mineral gain that occurred at different ages. After an initial period with slight increases in BMC and BMD values, we observed a period of rapid growth and accumulation of bone mass in the lumbar spine, especially striking after 10 and 11 years of age in girls and boys, respectively. This acceleration of bone mass gain between 10 and 14 years of age, occurring later in males, has been extensively documented in the literature $(2,7,10,11,15-18)$ and seems to be associated with pubertal growth. Unfortunately, Tanner pubertal state, which could have partially explained the increase in bone mass, could not be evaluated.

The striking increase in BMC and BMD, reaching values similar to those expected for young Brazilian adults (12), demonstrates 
the importance of this period for reaching an adequate peak of bone mass. However, this increase in bone mass variables does not only reflect the real increase in BMD, but also the increase of bone volume that occurs with growth.

In DXA, like in other projection methods, BMD is calculated from the BMC expressed as $\mathrm{g}$ and the projected area of the region of interest (in this case, vertebral body) without taking bone thickness into account. Thus, the increase in bone size causes an unreal increase in BMD obtained by this method. Since the vertebrae are complex structures that grow in all dimensions during childhood and adolescence, it is justifiable to suppose that this method underestimates the BMD value of smaller children and overestimates that of larger ones. In disease states in which disorders of growth occur, this systematic error can produce distortions in the results, making the evaluation of BMD by DXA cumbersome (19).

In order to minimize this error, Katzman et al. (8) and Kröger et al. (10) introduced some equations elaborated in order to obtain "corrected" or "volumetric" BMD (vBMD), expressed as $\mathrm{g} / \mathrm{cm}^{3}$. Although these "corrected" values still present distortions, the vBMD curves obtained by these investigators showed an increase with age that was less intense than those obtained from BMD without correction or "areal" BMD. These results confirm the limited data obtained for vBMD in the lumbar spine using quantitative computed tomography, which did not show a significant increase with age (20) or showed a little expansion of bone mass only during the pubertal period (21).

In our series, we observed a strong correlation between the BMC and BMD values and weight and height in both sexes. This close relationship between bone mass and anthropometric variables had already been identified in early studies by Mazess and Cameron (22) and was later confirmed in studies performed on bone from the appendicular bone structures $(19,23-28)$ and from the lumbar spine $(10,11,15,16,29,30)$.

For stepwise multiple regression analysis we decided to additionally use the variable VA (L2-L4) as done by De Priester et al. (26), who considered the values of bone width, obtained by screening, in the regression analysis when elaborating a predictive equation for BMC values of the forearm obtained by single photon absorptiometry.

Indeed, for multiple regression analysis by the stepwise method, VA $\left(\mathrm{cm}^{2}\right)$, chronological age (years), weight $(\mathrm{kg})$, and height $(\mathrm{cm})$ were used as independent variables, with BMC $(\mathrm{g})$ and BMD $\left(\mathrm{g} / \mathrm{cm}^{2}\right)$ as dependent variables. Borderline $P$ values were reached when only the VA and age were considered. The use of other variables (weight and height) after adjustment of VA and age did not prove to be significant in predicting BMC or BMD.

These results support the idea that correlations between BMD and the anthropometric variables weight and height are mainly due to the increase of bone dimensions during childhood and adolescence, and confirm that BMD depends on age and growth during this period.

Although in the present study we obtained equations for the predictive values of BMC and BMD for children and adolescents between 6 and 14 years of age with statistical significance and high coefficients of correlation, which permit comparisons with groups of sick children (31), the distinctive characteristics of our series call for additional studies in order to validate these equations for application to children from other parts of the country. 


\section{References}

1. Avioli LV \& Heaney RP (1991). Calcium intake and bone health. Calcified Tissue International, 48: 221-223.

2. Anderson JJ B \& Henderson RC (1991). Dietary factors in the development of peak bone mass. In: Burckhardt $P$ \& Heaney RP (Editors), Nutritional Aspects of Osteoporosis. Raven Press, New York, 3-19.

3. Bonjour J P, Theintz G, Law F, Slosman D \& Rizzoli P (1994). Peak bone mass. Osteoporosis International, 4 (Suppl 1): 7-13.

4. J ohnston CC \& Slemenda CW (1991). The relative importance of nutrition compared to the genetic factors in the development of bone mass. In: Burckhardt P \& Heaney RP (Editors), Nutritional Aspects of Osteoporosis. Raven Press, New York, 2125.

5. Rodin A, Murby B, Smith MA, Caleffi M, Feutiman I, Chapman MG \& Fogelman I (1990). Premenopausal bone loss in the lumbar spine and neck of femur: a study of 225 Caucasian women. Bone, 11: 1-5.

6. Gilsanz V, Gibbens DT, Carlson M, Boechat MI, Cann CE \& Schulz EE (1988). Peak trabecular vertebral density: a comparison of adolescent and adult females. Calcified Tissue International, 43: 260262.

7. Bonjour J P, Theintz G, Buchs B, Slosman $D$ \& Rizzoli $P$ (1991). Critical years and stages of puberty for spinal and femoral bone mass accumulation during adolescence. J ournal of Clinical Endocrinology and Metabolism, 73: 555-563.

8. Katzman DK, Bachrach LK, Carter DR \& Marcus R (1991). Clinical and anthropometric correlates of bone mineral acquisition in healthy adolescent girls. J ournal of Clinical Endocrinology and Metabolism, 73: 1332-1339.

9. Chesnut III CH (1989). Is osteoporosis a pediatric disease? Peak bone mass attainment in the adolescent female. Public Health Reports, 104 (Suppl): 50-54.

10. Kröger $\mathrm{H}$, Kotaniemi $A$, Kröger $L$ \& Alhava E (1993). Development of bone mass and bone density of spine and femoral neck. A prospective study of 65 children. Bone and Mineral, 23: 171-182.

11. Lu PW, Briody J N, Ogle GD, Morley K, Humphries IR, Allen J , Howman-Giles R, Sillence D \& Cowell CT (1994). Bone mineral density of total body, spine and femoral neck in children and young adults. A cross-sectional and longitudinal study. J ournal of Bone and Mineral Research, 9: 1451-1458.

12. Szejnfeld VL, Atra E, Baracat EC, Aldrighi J \& Civitelli R (1995). Bone density in white Brazilian women: rapid loss at time around the menopause. Calcified Tissue International, 56: 186-191.

13. Kröger $\mathrm{H}$, Kotaniemi $A$, Vainio $P \&$ Alhava $E$ (1992). Bone densitometry of the spine and femur in children by dual-energy $X$ ray absorptiometry. Bone and M ineral, 17: 75-85.

14. De Schepper J, Derde MP, Van den Broeck M, Piepsz A \& J onckheer $\mathrm{MH}$ (1991). Normative data for lumbar spine bone mineral content in children: influence of age, height, weight and puberal stage. J ournal of Nuclear Medicine, 32: 216-220.

15. Glaster $C$, Braillon $P$, David $L$, Cochat $P$, Meunier PJ \& Dalmas PD (1990). Measurement of bone mineral content of the lumbar spine by dual energy X-ray absorptiometry in normal children: correlations with growth parameters. J ournal of Clinical Endocrinology and Metabolism, 70: 1330-1333.

16. Southard RN, Morris JD, Mahan JD, Hayes J R, Torch MA, Sommer A \& Zipf WB (1991). Bone mass in healthy children: measurement with quantitative DXA. Radiology, 179: 735-738.

17. Boot AM, de Ridder MAJ, Pols AP, Krenning EP \& de M unick Keizer-Schrama SMPF (1997). Bone mineral density in children and adolescents: relation to puberty, calcium intake, and physical activity. J ournal of Clinical Endocrinology and Metabolism, 82: 57-62.

18. Warner JT, Cowan FJ, Dunstan FDJ, Evans WD, Webb DKH \& Gregory J W (1998). Measured and predicted bone mineral content in healthy boys and girls aged 8-16 years. Acta Paediatrica, 87: 244249.

19. Molgaard C, Lykke Thomsen B \& Michaelsen KF (1998). Influence of weight, age and puberty on bone size and bone mineral content in healthy children and adolescents. Acta Paediatrica, 87: 494-499.

20. Mora S, Goodman WG, Loro ML, Roe TF \& Gilsanz V (1994). Age-related changes in cortical and cancellous vertebral bone density in girls: assessment with quanti- tative CT. American J ournal of Roentgenology, 162: 405-409.

21. Gilsanz V, Gibbens DT, Roe TF, Carlson $M$, Senge HO, Boechat MI, Huang HK, Schulz EE, Libanati CR \& Cann CC (1988). Vertebral bone density in children: effect of puberty. Radiology, 166: 847-850.

22. Mazess RB \& Cameron J R (1971). Skeletal growth in school children: maturation and bone mass. American J ournal of Physical Anthropology, 35: 399-408.

23. Specker B, Brazerol W, Tsang R, Levin R, Searcy J \& Steichen J (1987). Bone mineral content in children 1 to 6 years of age. American J oumal of Diseases of Children, 141: 343-344.

24. Landin L \& Nilssen BE (1981). Forearm bone mineral content in children: normative data. Acta Paediatrica Scandinavica, 70: 919-923.

25. Li J Y, Specker BL, Ho ML \& Tsang RC (1989). Bone content in black and white children into 6 years of age. American J ournal of Diseases of Children, 143: 1346-1349.

26. De Priester JA, Cole TJ \& Bishop NJ (1991). Bone growth and mineralization in children aged 4 to 10 years. Bone and Mineral, 12: 57-65.

27. Bell NH, Shary J, Stevens J, Garza M, Gordon L \& Edwards J (1991). Demonstration that bone mass is greater in black than in white children. J ournal of Bone and Mineral Research, 6: 719-723.

28. Troverbach WT, Man SA, Gommers D, Zwamborn AW \& Grobbee DE (1991). Determinants of bone mineral content in childhood. Bone and Mineral, 13: 55-67.

29. Dhuper S, Warren MP, Brooks-Gunn J \& Fox R (1990). Effects of hormonal status on bone density in adolescent girls. J ournal of Clinical Endocrinology and Metabolism, 71: 1083-1088.

30. Ponder SW, McCormick DP, Fawcett $D$, Palmer J L, McKernan MG \& Brouhard BH (1990). Spinal bone mineral density in children aged 5.00 through 11.99 years. American J ournal of Diseases of Children, 144: 1346-1348.

31. Goldenberg J , Fonseca AS, Len C, Hilário MO, Szejnfeld V \& Atra E (1992). Bone density in juvenile systemic lupus erythematosus. American College of Rheumatology, 56th Annual Scientific Meeting, Atlanta, GA, Abstract C135. 